\title{
Leucocyte function in patients with rheumatoid arthritis: quantitative in-vivo leucocyte mobilisation and in-vitro functions of blood and exudate leucocyt
}

\author{
J H WANDALL
}

From the Department of Medical Gastroenterology C, Herlev Hospital, University of Copenhagen, Denmark.

SUMMARY Quantitative leucocyte mobilisation in vivo and the in-vitro random migration $\frac{\omega^{2}}{2}$ chemotaxis, phagocytosis, and oxidative metabolic activity were studied in 15 patients witl rheumatoid arthritis (RA). Patients mobilised leucocytes to chambers covering skin windows ti் the same degree as control subjects, and the mobilisation correlated with the blood leucocyt numbers and serum concentration of $\alpha$-l-antitrypsin. Peripheral blood leucocytes showed slightlyp reduced migration in Boyden chambers but increased phagocytosis and increased unstimulate $\mathbb{Q}$ reduction of nitroblue tetrazolium. Exudate leucocytes from patients with RA showed migratory and phagocytic activity which did not differ from that of control subjects, but unstimulate exudate leucocytes reduced nitroblue tetrazolium more actively than leucocytes from contro $\overrightarrow{\&}$ subjects. The observations indicate that leucocyte accumulation at an experimental inflammator ${ }^{\Phi}$ lesion and the function of these exudate leucocytes are not impaired in patients with rheumatgide arthritis.

Key words: neutrophil leucocyte function, skin chambers.

Abnormal functions of polymorphonuclear leucocytes (PMNs) have been found in rheumatoid arthritis-namely, reduced chemotactic function and metabolic responses to phagocytic stimuli by blood PMNs. ${ }^{12}$ Reduced chemotaxis, ${ }^{3}$ phagocytosis, ${ }^{45}$ and metabolic activity ${ }^{4}$ have also been found in PMNs from joint effusions.

During an inflammatory reaction leucocytes are mobilised from the blood to the inflammatory lesion, and the exudate leucocytes show a markedly increased phagocytosis and metabolic activity in healthy subjects. ${ }^{6}$ Impaired function of joint fluid leucocytes from patients with rheumatoid arthritis may therefore indicate that either factors occurring locally modify the PMN function or that the exudate PMNs are functionally altered in a different manner in patients with rheumatoid arthritis compared with healthy subjects.

The aims of this investigation were to study the mobilisation of leucocytes in vivo in patients with

Accepted for publication 19 March 1985.

Correspondence to $\mathrm{Dr} \mathrm{J} \mathrm{H}$ Wandall, Department of Medical Gastroenterology, Frederiksberg Hospital, 57 Ndr Fasanvej. Copenhagen F, Denmark DK-2000. rheumatoid arthritis and the function of PMNs from exudate and blood in vitro.

Patients and methods

PATIENTS WITH RHEUMATOID ARTHRITIS Fifteen patients (five female, 10 male; median age 55 years, range $33-74$ years) with a median duration. of disease of three years (range 0-25 years) were studied. Thirteen patients had classical disease an $\bar{\oplus}$ two had definite disease according to the criteria of the American Rheumatism Association. All patients were non-febrile, without other diseases and were. not receiving any medication at the time of study Any previous treatment with steroids had beef discontinued for more than six months, with goldy salts for one month, and for all other drugs eightw days. The disease was active in terms of morning stiffness ( $>45 \mathrm{~min}$ ) and tender joints ( $>$ five joints)

Informed consent was received from all patient before the study.

CONTROL GROUP

Healthy volunteers ( 11 female, 10 male; median ag 
30 years, range $20-68$ years) served as controls. All had normal blood leucocytes and differential counts and normal serum concentrations of $\alpha$-l-antitrypsin.

LEUCOCYTE MOBILISATION TEST

Leucocyte mobilisation in vivo was quantified by a modification of the skin chamber technique. ${ }^{7}$ Epidermis on the volar aspect of the forearm was abraded with a surgical scalpel until the papillary layer was visible as vivid red pin-points; no bleeding was allowed. The abrasion was immediately covered with a chamber and filled with autologous serum. At fixed intervals the chamber was drained and refilled with fresh autologous serum. The leucocytes from the chamber were isolated by centrifugation, counted in a haemocytometer, and the total number of leucocytes from the chamber was calculated. A differential white cell count was also performed on stained coverslip preparations by counting 200 consecutive cells.

Mobilisation was expressed as the total number of leucocytes per $\mathrm{cm}^{2}$ abrasion after 12, 24, 36, and 48 hours. The kinetics of mobilisation were expressed as the leucocyte migration rate-namely, the number of leucocytes per hour per $\mathrm{cm}^{2}$ abraded area.

IN-VITRO LEUCOCYTE FUNCTION TEST

The function of leucocytes in vitro was studied by methods previously described in detail. ${ }^{6}$ Blood leucocytes were isolated from the leucocyte rich plasma after sedimentation of erythrocytes by methylcellulose (for chemotaxis) or dextran (for phagocytosis). Exudate leucocytes were isolated from chambers covering skin windows. To ensure that only newly migrated leucocytes were studied the leucocytes were allowed to accumulate for only two hours at each time point $(20-22,22-24$, and 46-48 hours after establishing the skin window).

A S ESSMENT OF CHEMOTAXIS

Leucocytes $\left(1.25 \times 10^{6}\right)$ in autologous plasma or in Hanks's balanced salt solution ( $\mathrm{pH} 7 \cdot 3$; HBSS) were layered on to cellulose ester filters (pore size $3 \mu \mathrm{m}$, Millipore SA, France) and incubated in modified Boyden chambers. ${ }^{6}$ Casein ( $5 \mathrm{~g} / \mathrm{l}$ in HBSS; Merck, FRG) was chosen as the chemoattractant, since its effects are independent of serum factors. Unstimulated migration was assayed in chambers containing HBSS alone. After incubation (three hours; $37^{\circ} \mathrm{C}$ ) the filters were fixed, stained, and mounted on microscope slides. Migration was quantified by the 'leading front method', which gave the maximal migration in micrometres by a minimum of two leucocytes in five random microscopic fields at a magnification of 400 and by a chemotactic index,namely, the number of leucocytes located $50 \mu \mathrm{m}$ inside the filters per thousand cells on the starting surface. All samples were measured in duplicate.

ASSESSMENT OF PHAGOCYTOSIS

Paraffin oil emulsion coloured with oil-red-O was used to measure the initial rate of phagocytosis. Phagocytosis independent of serum factors was measured by the uptake of emulsion made with bovine serum albumin and serum dependent phagocytosis by the uptake of emulsion made with lipopolysaccharide from Escherichia coli 026B6 (Boivin method, Difco, USA) opsonised (15 min, $37^{\circ} \mathrm{C}$ ) with fresh autologous serum. Leucocytes were incubated with emulsion in a shaking bath for $4 \mathrm{~min}$ at $37^{\circ} \mathrm{C}$. After incubation the uningested oil was removed by centrifugation and the phagocytosed oil extracted with $p$-dioxan $(1 \mathrm{ml}, 1 \mathrm{~h})$ and measured colorimetrically at $525 \mathrm{~nm}$ (Zeiss PM4). The amount of phagocytosed oil was calculated from the extinction and given as $\mathrm{mg}$ oil per min per $10^{7}$ phagocytes. All samples were measured in duplicate (difference $<10 \%$ ).

\section{NITROBLUE TETRAZOLIUM (NBT) \\ REDUCTION}

NBT reduction to formazan was used to measure the oxidative metabolic activity. Leucocytes were incubated as for the assay of phagocytosis, but the medium contained NBT at a final concentration of $0.6 \mathrm{mmol} / \mathrm{l}^{6}$ The formazan generated was extracted with $p$-dioxan $\left(1 \mathrm{ml} ; 85^{\circ} \mathrm{C}, 25 \mathrm{~min}\right)$ and measured colorimetrically at $580 \mathrm{~nm}$. Resting leucocyte activity was expressed as the change in extinction per 8 min per $10^{7}$ phagocytes. Reduction of NBT during phagocytosis of lipopolysaccharide coated oil-red-O emulsion was expressed as the change in extinction per mg phagocytosed oil after correction for resting cell activity and differences in phagocytosis. All samples were measured in duplicate (difference $<15 \%$ ).

DETERMINATION OF $\alpha-1$-ANTITRYPSIN Serum concentrations of $\alpha$-l-antitrypsin were measured by rocket immunoelectrophoresis against monospecific antibodies (DAKO Immunoglobulins, Denmark) with a commercial serum as reference (ORDT, Behringwerke, FRG).

\section{S T A T I S T I C S}

The Mann-Whitney rank sum test for unpaired data, Wilcoxon's test for paired data, and the Spearman rank correlation test were applied. All values given in the text are median values and observed range. 
Table 1 Concentration of leucocyte subpopulations in peripheral blood from patients with rheumatoid arthritis $(n=15)$ and healthy controls $(n=21)$. Values given are median value and range

\begin{tabular}{|c|c|c|c|c|c|c|}
\hline & \multicolumn{2}{|c|}{ Neutrophils } & \multirow{2}{*}{$\begin{array}{l}\text { Lymphocytes } \\
I 0^{4} / l\end{array}$} & \multirow{2}{*}{$\begin{array}{l}\text { Monocytes } \\
I 0^{4} / l\end{array}$} & \multirow{2}{*}{$\begin{array}{l}\text { Eosinphils } \\
10^{4} l l\end{array}$} & \multirow{2}{*}{$\begin{array}{l}\alpha-l-A \text { ntitrypsin } \\
g / l\end{array}$} \\
\hline & $10^{4} / l$ & $\begin{array}{l}\text { Mean number of } \\
\text { nuclear segments }\end{array}$ & & & & \\
\hline Rheumatoid arthritis & $\begin{array}{l}3 \cdot 0 \\
(1 \cdot 5-4 \cdot 9)\end{array}$ & $\begin{array}{l}3 \cdot 2^{*} \\
(1 \cdot 8-4 \cdot())\end{array}$ & $\begin{array}{l}2 \cdot 1 \\
(0 \cdot 5-3 \cdot(0)\end{array}$ & $\begin{array}{l}263 \\
(29-592)\end{array}$ & $\begin{array}{l}142 \\
(0-340)\end{array}$ & $\begin{array}{l}2 \cdot 9 \\
(1 \cdot 5-6 \cdot 2)\end{array}$ \\
\hline Healthy controls & $\begin{array}{l}3 \cdot 0 \\
(1 \cdot 4-4 \cdot 5)\end{array}$ & $\begin{array}{l}2 \cdot 5 \\
(2 \cdot()-3 \cdot 4)\end{array}$ & $\begin{array}{l}2 \cdot 0 \\
(1 \cdot 2-3 \cdot 8)\end{array}$ & $\begin{array}{l}194 \\
(0-682)\end{array}$ & $\begin{array}{l}85 \\
((1-284)\end{array}$ & $\begin{array}{l}2 \cdot 4 \\
(1 \cdot 9-3 \cdot 5)\end{array}$ \\
\hline
\end{tabular}

${ }^{*} \mathrm{p}<0 \cdot 01$.

\section{Results}

Blood PMNs from patients showed hypersegmentation of the nuclei compared with controls (Table 1). Total white blood cell counts, PMN counts, and $\alpha-1$-antitrypsin concentrations did not differ significantly from control values.

\section{LEUCOCYTE MOBILISATION IN VIVO}

The same number of leucocytes accumulated in the chambers from patients and controls (Table 2), and the kinetics of the mobilisation as given by the migration rate did not differ from controls (Fig. 1). The total white blood cell count correlated with the number of leucocytes mobilised after 24 hours (Spearman's rank $\mathrm{r}=0.6598 ; \mathrm{p}<0 \cdot() 2)$ and 48 hours $(\mathrm{r}=0.6080 ; \mathrm{p}<0 \cdot(05)$. The serum concentration of $\alpha$-l-antitrypsin also correlated with the mobilisation after $12 \quad(\mathrm{r}=0.7571 ; \mathrm{p}<0.01), 24 \quad(\mathrm{r}=0.6143$; $\mathrm{p}<0.05)$, and 48 hours $(\mathrm{r}=0.5286 ; \mathrm{p}<0.05)$.

The leucocytes mobilised were predominantly PMNs $(85-100 \%)$ with fewer lymphocytes $(0-5 \%)$ and macrophages $(0-14 \%)$. There were no differences between patients and controls.

\section{LEUCOCYTE FUNCTION IN VITRO}

Chemotactic function

Figs 2 and 3 summarise the results from the

Table 2 Cumulative leucocyte mobilisation in skin windows of patients with rheumatoid arthritis $(n=15)$ and healthy controls. Values given are the median value and range of leucocytes per $\mathrm{cm}^{2}$ epidermal abrasion

\begin{tabular}{lrrrrr}
\hline $\begin{array}{l}\text { Hours after } \\
\text { start of } \\
\text { skin window }\end{array}$ & \multicolumn{2}{l}{ Rheumatoid arthritis } & \multicolumn{2}{l}{ Healthy controls } \\
\cline { 2 - 3 } \cline { 5 - 6 } & Median & Range & Median & \multicolumn{1}{c}{ Range } \\
\hline 12 & $27 \times 10^{6}$ & $(6-46)$ & $20 \times 10^{6}$ & $(10-61)$ \\
24 & $71 \times 10^{6}$ & $(30-107)$ & $70 \times 10^{6}$ & $(50-113)$ \\
36 & $112 \times 10^{6}$ & $(56-201)$ & $145 \times 10^{6}$ & $(102-261)$ \\
48 & $165 \times 10^{6}$ & $(88-300)$ & $200 \times 10^{6}$ & $(160-413)$ \\
\hline
\end{tabular}

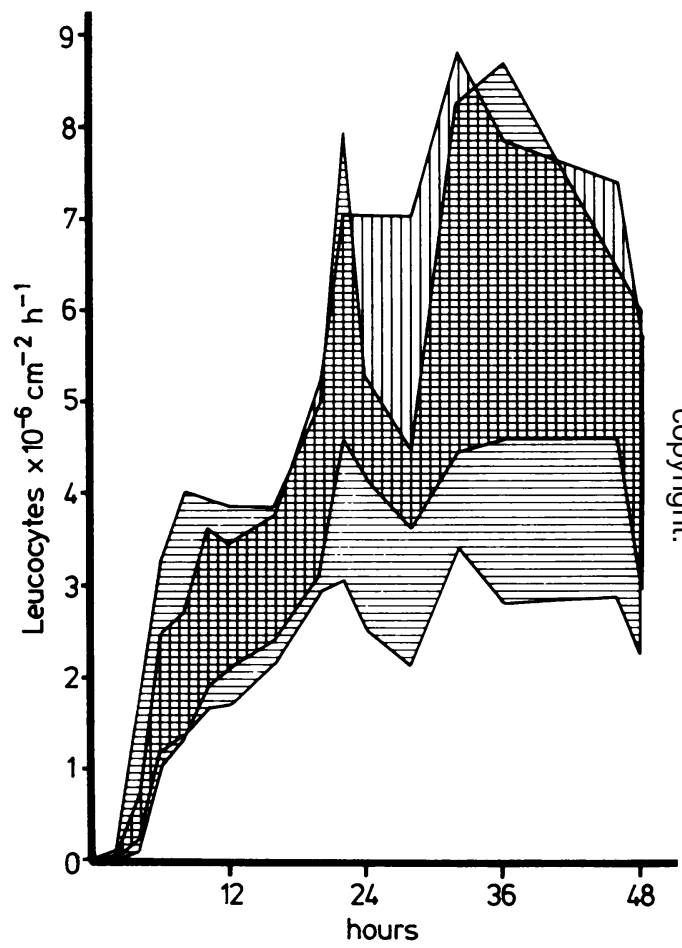

Fig. 1 Leucocvte migration rate in patients $(n=15)$ and healthy subjects $(n=21)$. The hatched area indicates tho 25/75 percentile. 目 Rheumatoid arthritis; 四 healthy controls.

unstimulated and stimulated migration of blood and exudate leucocytes.

Blood leucocytes. Leucocytes from patiento showed a reduced unstimulated migration a $\bar{\Phi}$ measured by the leading front method (patients:? median $77 \mu \mathrm{m}$; controls: median $97 \mu \mathrm{m} ; \mathrm{p}<0 \cdot 01$. Fig. 2). If leucocytes were suspended in plasma the migration did not differ from controls (Fig. 2). N@ 

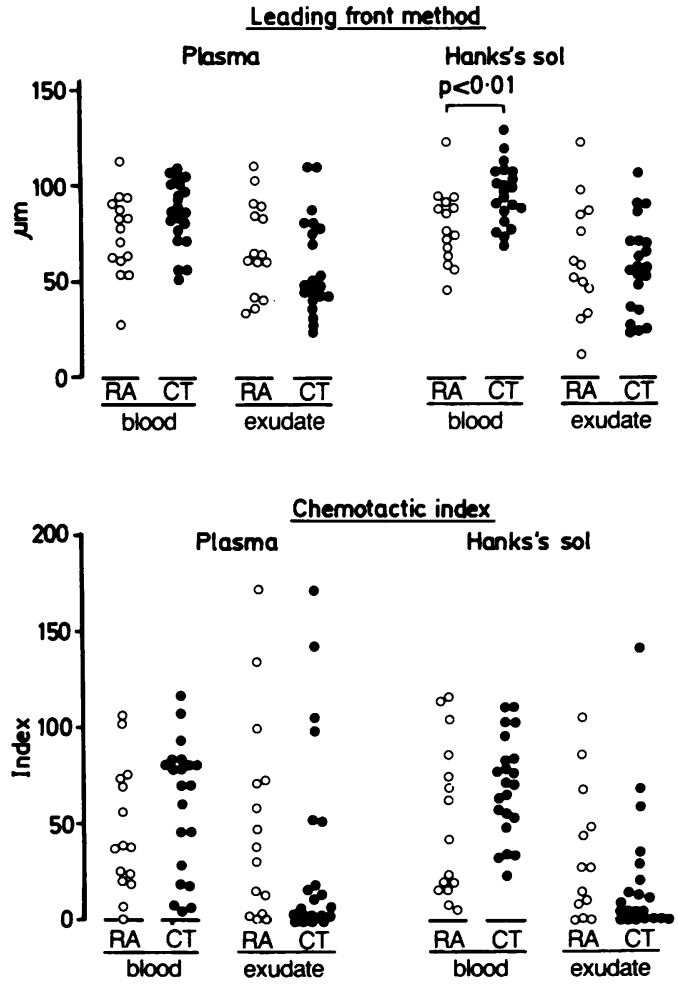

Fig. 2 Unstimulated migration of blood and exudate leucocytes from patients with rheumatoid arthritis $(R A)$ and healthy control subjects (CT). Results obtained by the leading front method (top) and by the chemotactic index are given for cells in plasma and Hanks's solution. Differences between patients and controls are indicated.

differences could be shown in the chemotactic index between patients and controls.

The casein stimulated migration by leucocytes in HBSS from patients was reduced (patients: median 125; controls: median 166; $\mathrm{p}<0.05$; Fig. 3 ). No differences were found if leucocytes were suspended in plasma or if the migration was measured by the leading front.

Exudate leucocytes. No differences were found between the exudate leucocytes from patients and controls (Figs 2 and 3). No differences were shown between the migration of exudate and blood leucocytes in patients.

\section{PH A G OCY TOS IS}

Fig. 4 summarises the phagocytic activity of blood and exudate leucocytes.

Blood leucocytes. No differences were found between leucocytes from patients and controls after 24 hours. After 48 hours, however, both serum independent and dependent phagocytosis by leucocytes from patients were increased compared with control leucocytes (Fig. 4).

Exudate leucocytes. Phagocytosis by exudate leucocytes from patients did not differ from controls after 24 or 48 hours. Exudate leucocytes were more phagocytic than blood leucocytes in both patients $(p<0.01)$ and controls $(p<0.01)$. Serum dependent phagocytosis by exudative leucocytes was correlated with blood leucocyte function in patients (at 24 hours: $r=0.6045 ; p<0.05$; at 48 hours: $r=0.6714$; $p<0.05$ ) and in controls (at 24 hours: $r=0.7480$; $\mathrm{p}<0.001$; at 48 hours: $\mathrm{r}=0.6061 ; \mathrm{p}<0 \cdot 02)$. Serum independent phagocytosis by exudate leucocytes did not correlate with the blood leucocyte activity.
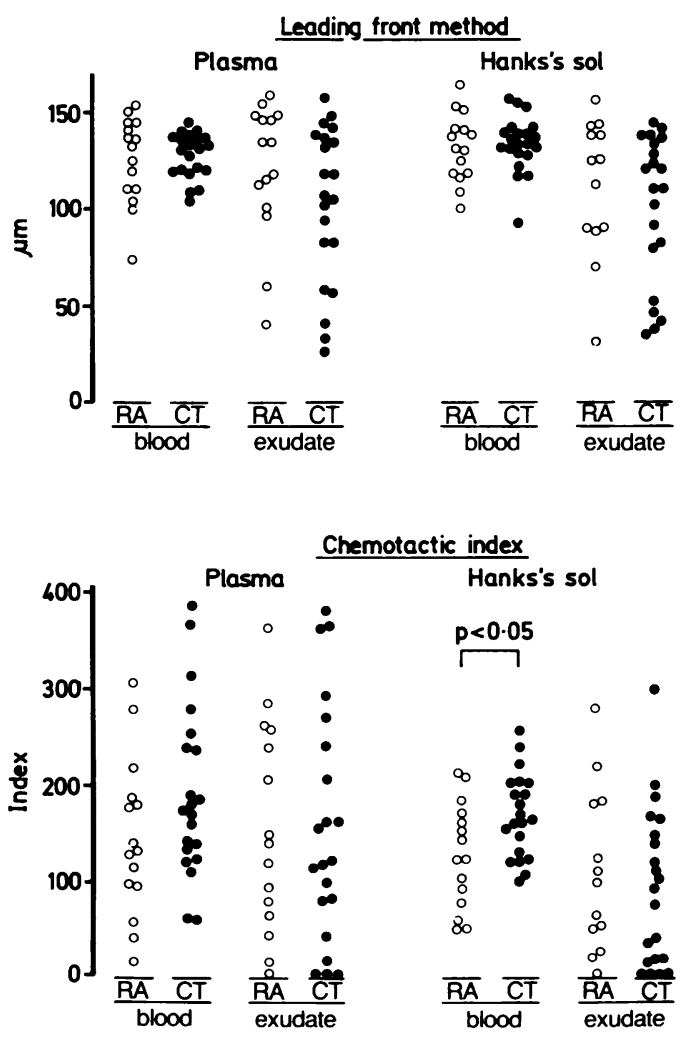

Fig. 3 Casein stimulated migration of blood and exudate leucocytes from patients with rhe'umatoid arthritis (RA) and control subjects (CT). Results obtained by the leading front method (top) and by the chemotaclic index are given for cells in plasma and Hanks's solution. Differences between patients and controls are indicated. 

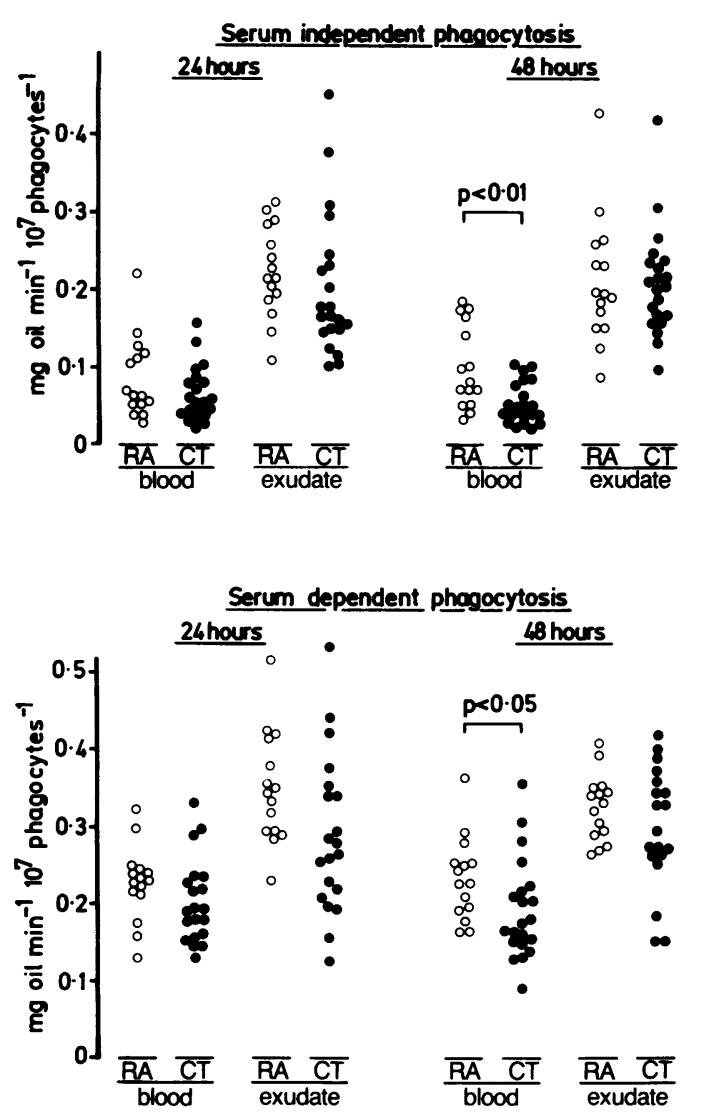

Fig. 4 Serum independent (top) and dependent (bottom) phagocytosis by exudate and blood leucocytes from patients with rheumatoid arthritis $(R A)$ and control subjects $(C T)$. Values shown were obtained 24 and 48 hours after establishing skin windows. Differences between patients and control subjects are indicated.

NITROBLUE TETRAZOLIUM REDUCTION Blood leucocytes. There was an increased unstimulated NBT reduction by leucocytes from patients compared with controls (Fig. 5). The reduction of NBT during phagocytosis (data not shown) did not show any differences between patients and controls.

Exudate leucocytes. Leucocytes from patients showed increased unstimulated NBT reduction when compared with control leucocytes after 24 and 48 hours. There was no correlation between exudate and blood leucocyte reduction of NBT.

Reduction of NBT during phagocytosis by leucocytes from patients and controls did not show any differences (data not shown).

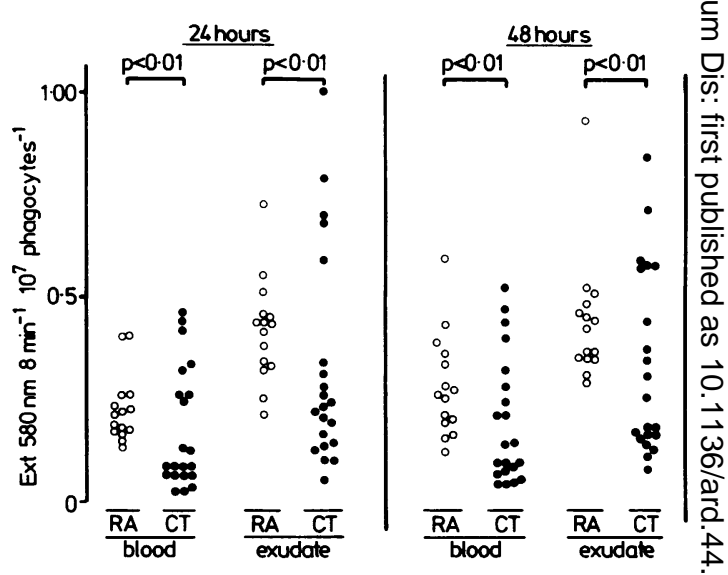

Fig. 5 Unstimulated reduction of nitroblue tetrazolium $b \vec{\rho}$ exudate and blood leucocytes 24 and 48 hours after establishing the skin windows. Differences between rheumatoid arthritis patients (RA) and controls (CT) arg indicated.

\section{Discussion}

Patients with rheumatoid arthritis were found in study to mobilise leucocytes to skin windows in 通然 same numbers as controls. This is at variance wit Walker et al. ${ }^{8}$ but in agreement with Segal ano Loewi. ${ }^{9}$ Walker et al. ${ }^{8}$ found a markedly reduceof accumulation of leucocytes after 24 hours. How ever, the patients from that study had received medication with steroids, gold salts, and non $\frac{0}{3}$ steroidal anti-inflammatory drugs. All these drugs are known to inhibit PMN migration in vivo ${ }^{10} 11$ and in vitro. ${ }^{12-14}$

Reduced mobilisation of leucocytes to skiñ windows is found in other inflammatory states ${ }^{15-1}$ 든 and is a striking phenomenon in patients with granulomatous reaction such as that in Crohn'so disease. $^{916}$ The finding of normal mobilisation in patients with rheumatoid arthritis is therefore suprising and might indicate a difference in the inflammatory reaction in such patients. This latte? concept is supported by the positive correlation between the mobilisation of leucocytes, the tota? white blood cell count, and the serum concentration 5 of an acute phase protein ( $\alpha$-l-antitrypsin).

Blood leucocytes from patients showed hyperseg: mentation of the nuclei. This has been found before, ${ }^{18}$ but the cause of hypersegmentation is్ unexplained.

Blood leucocytes from patients showed a reducedo unstimulated migration in vitro and reduced stimu lated migration. There was no inhibitory effect of

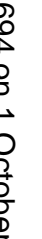


the plasma. The results of previous studies of leucocyte chemotaxis have been conflicting. Reduced chemotaxis has been found by some workers, ${ }^{214}$ whereas others have observed normal chemotaxis. ${ }^{3819}$ Their results are difficult to compare with the present study, since different assays and chemoattractants were applied. In addition, the disease activity and medication were also different. Nevertheless, sera from patients with rheumatoid arthritis inhibit leucocyte chemotaxis, and ingestion of immune complexes has been suggested to cause reduced chemotaxis. ${ }^{20}$

Exudate leucocytes from patients were as functionally active as leucocytes from healthy controls. Leucocytes isolated from synovial joint fluid have been found to be chemotactically impaired ${ }^{3}$ and to show reduced phagocytosis of staphylococci ${ }^{4}$ and Candida albicans. ${ }^{21}$ A defect of complementmediated phagocytosis by joint and blood leucocytes has been shown, and a defective receptor for the $\mathrm{C} 3 \mathrm{~b}$ opsonin of the complement system was suggested. ${ }^{21}$ Phagocytosis of lipopolysaccharide emulsion requires activation of the alternative pathway and fixation of $\mathrm{C} 3 \mathrm{~b}$ to the oil droplets. ${ }^{22}$ Thus the present findings cannot support this concept of a defective receptor for $\mathrm{C} 3 \mathrm{~b}$ on PMNs from patients with rheumatoid arthritis.

Both blood and exudate leucocytes spontaneously generated formazan from NBT at increased rates in this study. A normal NBT reduction was found in a previous study by the histochemical method. ${ }^{23} \mathrm{~A}$ recent report ${ }^{24}$ has shown an increased oxidative metabolic activity of synovial fluid leucocytes measured by chemiluminescence. Reduction of NBT and the chemiluminesence reflect the generation of active oxygen radicals which are known to mediate tissue destruction. ${ }^{25}$

The present study described the function of leucocytes from an experimental inflammatory lesion and the leucocytes were as functionally active as those from healthy subjects. In contrast, leucocytes isolated from synovial fluid have been found to be functionally impaired. If the present study is correct, then it follows that a functional defect of exudate leucocytes in patients with rheumatoid arthritis may be limited to the cells within the joint.

In conclusion, the mobilisation and function of exudate leucocytes in skin windows of patients with rheumatoid arthritis are not different from those seen in healthy subjects. The results indicate that the reduced function of synovial fluid leucocytes probably reflects changes occurring within the joint space. The mobilisation in vivo correlated with other indicators of inflammation, and it is suggested that increased numbers of leucocytes may be mobilised with increasing inflammatory activity. Studies of patients with different disease activities will be necessary in order to clarify this assertion.

The study was supported by the Danish Medical Rescarch Council (No 512-7257) and Johan and Hanne Weimann ncé Scedorffs foundation. A $L$ Poulsen, $H$ Kaargaard, and $H$ Furhauge are thanked for excellent assistance. Dr K Sørensen MD. Herlev Hospital (now deceased) kindly allowed me to study patients under his care.

\section{References}

1 Corberand J. Ambigues H. Larrad B, Praderc J. Neutrophil function in rheumatoid arthritis. Scand J Rheumatol 1977; 6: 49-52.

2 Mowat A G, Baum J. Chemotaxis of polymorphonuclear leucocytes from patients with rheumatoid arthritis. J Clin Invest 1971; 50: 2541-9.

3 Kemp S A, Brown S, Brooks P M, Ncoh S H. Migration of blood and synovial fluid neutrophils obtained from patients with rheumatoid arthritis. Clin Exp Immunol 1980); 39: 240-6.

4 Bodel P T, Hollingsworth J W. Comparative morphology, respiration and phagocytic function of lcucocytes from blood and joint fluid in rheumatoid arthritis. J Clin Invest 1966; 45: $580-9$.

5 Turner R A, Schumacher H R, Mycrs A R. Phagocytic function of polymorphonuclear leucocytes in rheumatic disease. J Clin Invest 1973; 52: 1632-5.

6 Wandall $\mathrm{J} \mathrm{H}$. Function of polymorphonuclcar ncutrophilic leucocytes. Comparison of leucocytes from blood and from exudate in healthy voluntecrs. Acta Pathol Microbiol Immunol Scand /CI 1982; 90: 7-13.

7 Wandall J H. Lcucocytc mobilisation to skin Icsions. Studics using a skin chamber technique in healthy voluntecrs. Acta Pathol Microbiol Immunol Scand /C/ 1980; 88: 255-61.

8 Walker J R, James D W. Smith J H. Directed migration of circulating polymorphonuclear lcucocytes in paticnts with rheumatoid arthritis. A defect in plasma. Ann Rheum Dis 1979; 38: $215-8$.

9 Segal A W, Locwi G. Neutrophil dysfunction in Crohn's discase. Lancet 1976; ii: 219-21.

10 Warne P J, West G B. Inhibition of leucocyte migration by salicylates and indomethacin. J Pharm Pharmacol 1978; 30: 783-5.

11 Peters W P, Holland J F, Senn . H J, Rhomberg W, Banerjee T. Corticosteroid administration and localized leucocyte mobilization in man. $N$ Engl $J$ Med 1972; 282: 342-5.

12 Dahinden C, Fehr J. Receptor directed inhibition of chemotactic factor induced neutrophil hyperactivity by pyrazolon derivatives. J Clin Invest 1980; 66: 884-91.

13 Ketchel M M, Favour C B, Sturgis S H. The in vitro action of hydrocortisone on leucocyte migration. J Exp Med 1980; 107: 211-8.

14 Mowat A G. Neutrophil chemotaxis in rheumatoid arthritis. Effect of D-penicillamine, gold salts and levamisole. Ann Rheum Dis 1978; 37: 1-8.

15 Wandall $\mathrm{J} \mathrm{H}$, Binder $\mathrm{V}$. Leucocyte function in ulcerative colitis. Quantitative lcucocytc mobilisation and function of blood leucocytes in vitro. Gut 1982; 23: 758-65.

16 Wandall $\mathrm{J} \mathrm{H}$, Binder V. Leucocyte function in Crohn's discase. Studics using a quantitative skin window technique and on the function of circulating polymorphonuclear lcucocytes in vitro. Gut 1982; 23: 173-80.

17 Wandall $\mathrm{J} \mathrm{H}$. Leucocytc mobilization and function in vitro of blood and exudative leucocytes after inguinal herniotomy. BrJ Surg 1982; 69: 669-72.

18 Edwin E. The scgmentation of polymorphonuclear neutrophils in rhcumatoid arthritis and ankylosing spondylitis. Acta Rheumatol Scand 1969: 15: 121-5. 
19 Udén A-M. Trang L. Venizelos N. Palmblad J. Neutrophil functions and clinical performance after total fasting in patients with rheumatoid arthritis. Ann Rheum Dis 1983: 42: 45-51.

20 Kemp A S. Roberts-Thompson P. Neoh S H. Brown S. Inhibition of neutrophil migration by sera from patients with rheumatoid arthritis. (lin Exp Immunol 1978: 36: 423-9.

21 Wilton J M A. Gibson T. Chuck C M. Defective phagocytosis by synovial fluid and blood polymorphonuclear leucocytes in patients with rheumatoid arthritis. Nature of the defect. Rheumatol Rehabil 1978: suppl: 25-36.

22 Stossel J P. Alper ( A. Rosen F S. Scrum dependent phagocytosis of paraffin oil emulsified with bacterial lipopoly $\frac{\overline{5}}{\overline{3}}$ saccharide. J Exp Med 1973: 137: 690-7015.

23 Wenger $M$ E. Bole $G G$. Nitroblue tetrazolium dye reductionos by peripheral leucocytes from rheumatoid arthritis and systemic lupus erythematosus patients measured by a histochemical ances spectrophotometric method. J Lab Clin Med 1973: 82: 513-21-

24 James D W. Betts H. Cleland L G. Chemiluminescense of polymorphonuclear leukocytes from rheumatoid arthritis. Rheumatol 1983; 10: 184-9.

25 Weissmann G. Smolen J E. Hoffstein S. Polvmorphonuclea leucocytes as secretory organs of inflammation. J Inves Dermatol 1978: 71: 95-9.

\section{Book review}

Textbook of Rheumatology. 2nd edn. Eds. W M Kelley, E D Harris, S Ruddy, C B Sledge. Pp. 1972. $£ 160 \cdot 00$. Holt-Saunders: Eastbourne. 1985 .

The second edition of Kelley. Harris, Ruddy, and Sledge is for those who are strong-intellectually, physically, and financially. The copy reviewed here was the single volume version (it is available also in two volumes) and weighed in at $4.3 \mathrm{~kg}$ for its 1972 pages. compared with the fifth edition of Copeman at $3 \cdot() \mathrm{kg}$ for 1053 pages. It represents a considerable achievement on the part of the editors. coming only four years after the first edition. The blockbuster approach to achieving comprehensiveness is again apparent throughout. There are 131 authors (seven British), and the book is dedicated to no less than 17 individuals.

The plan of this volume remains much the same as in the first. The 'scientific bases of rheumatology' get 359 pages. general approach to the patient 185 , diagnostic tests 171 . clinical pharmacology 162 . clinical diseases 890 ), rehabilitation 18, and reconstructive surgery 181 . Predictably, the 'scientific basis' sections are very detailed, many of the individual chapters containing 200-300 references. This is hardly the stuff with which to curl up in front of the fire after a long day but. like the Oxford English Dictionary, it is comforting to know that it is available on the shelf to be consulted as the authority. The discerning buyer will. however, not fail to note that the shelf life of the $O E D$ is rather longer than that of this volume. My samplings suggest that these 'preclinical' chapters have been prepared with both thoroughness and authority. If one were faced with preparing a review or a lecture about aspirin. where better to start than the 20) closely printed pages of text, predictably well written, by Paul Plotz? One would hardly need to consult the 420 references which he quotes.

The mainly North American flavour of the clinical sections provides some interesting comparisons for the British reader. American rheumatology has always laid claim more firmly to wider areas of clinical immunology than is the case in Britain. This is reflected in the length of the chapters devoted to immunodeficiency (19 pages). dysproteinaemias (13). and amyloidosis (14). compared for example with the seven pages on polymyalgia rheumatica and giant cell arteritis. Curiously absent is any editorial recognition of the movement to bring the allied professionals' more into the rheumatology scene. The management of patients with rheumatic diseases depends so much on the work and skills of nurses. physiotherapists and occupational therapists that one might expect some discussion about the particular contributions of these $\stackrel{+}{+}$ professional groups. My reading of selected samples of th clinical descriptions of rheumatic diseases suggests thab these are both comprehensive and authoritative. Howevere parts of the section on reconstructive surgery, for exampleo those dealing with synovectomy of the rheumatoid knee and hip. if not uncritical. certainly promote a more enthusiastic and aggressive policy than that favoured bn most British rheumatologists

Throughout the text I got the feeling that both author and editors had done their work with thoroughness and careful attention to detail. An example of this is $\$ €$ relatively large numbers of diagrams. Many of these areor excellent quality and greatly enhance the text. subediting also appears to have been meticulous. printing and layout are satisfactory, the double colump format having comfortable proportions which make fo, easy reading. Most important, the quality of reproductio of $x$-rays is generally good. However. not all the author $\$$ understand the importance of trimming radiographs so a $\vec{\delta}$ to include only the essentials, nor of resisting the tempta3 tion to include paired joints when one (at twice the size gives such better definition. The histological and clinicas illustrations are adequate. First prize must go to Doctor Altman and Tenenbaum for their photograph of th patient with periostitis sleeping while standing on his head

Indexing is seldom complete in multiauthor textbooks and this one is no exception. A quick check under 'A failed to reveal acupuncture, aldolase, antistreptolysin. of Australia antigen, though all these words appear in the text. A cross check with the index of another volume o오ำ the same subject is easy to carry out, and it is curious that publishers do not take the trouble to do this.

The authors were presumably asked to regard compre hensive coverage of their subjects as the most importanP objective. Predictably this has led to much of the text beind rather ponderous in style. If this were necessary in order to achieve the authority of most of these chapters, then it is probably a price worth paying.

Overall the verdict must be that this new editiog represents a triumph for the editors. Every rheumatologis $\bar{D}$ will wish at least to have access to a copy for reference, but the cost is daunting.

Professor of Rheumatology

London Hospital Medical College 